\title{
TESTING OF ALPINISTS IN NORMOXIC AND HYPOXIC CONDITIONS, BEFORE AND AFTER HIGH-ALTITUDE EXPEDITIONS
}

\author{
Anton Ušaj \\ Laboratory of Biodynamics, Faculty of Sport, Slovenia
}

\begin{abstract}
The aim of the review was to present experimental results performed in the past 3 years in the Laboratory of Biodynamics. These results have brought to a novel point of view on alpinist adaptations influenced by climbing to (acclimatization) and descent from (deacclimatization) high-altitude expedition. Alpinists were tested before and after expeditions in normoxic and hypoxic conditions. The reduction of body weight, which accompanied alpinists during high-altitude expedition, affects some other parameters because of the increased relative energetic expenditure for the same absolute work. Heart rate $(H R)$ increased its values. However, because of possible simultaneous influence of training, which influences HR in opposite direction (decrease), values not show adaptation, probably due to masking of the phenomenon. Ventilation is parameter, which was affected by high-altitude hypoxia and reduced body weight in the same direction. Why increased $V_{E}$ observed during testing in normoxic conditions after high-altitude expedition was not observed also during testing in hypoxic conditions is not known. Arterial oxygen saturation is still elevated after a month of deacclimatization during testing in hypoxia. This was effect of acclimatization. Better oxygenation of arterial blood and brain was not found after a three weeks of deacclimatization from high-altitude expedition. However, it seems that a certain level of enhanced oxygenation persisted in exercising leg muscles. Local muscle oxygenation seems to be important during climbing at all. We observed forearm muscles oxygenation and found that muscles have been more oxygenated in trained alpinists and less in untrained.
\end{abstract}

Key words: acclimatization, deacclimatization, reacclimatization, training

\begin{abstract}
Alpinists performance during sea-level (normoxic) testing before and after high-altitude expedition

Alpinists climbing at high-altitude consist of walking up and down of the steep terrain (mountaineering), wearing additional weight of their equipment, and climbing rocks, snow and ice terrains. This includes push-ups their body by legs, squeezing of rocks details by hand fingers, squeezing the ice-axes and pull-ups by arms in different directions. During descending, their leg muscles contracts eccentrically, even several hours per day. When observing their adaptations, presented activities should be carefully analyzed and interpreted. The understanding of adaptations should be strictly related to interval and specific activities preceding the tests. This seems to be important especially when observing adaptations in leg muscles.

The performance of forearm muscles during isometric and dynamic contractions seems to be important and probably enhanced by climbing. During an isometric contraction at submaximal intensity, the motor units are not all recruited simultaneously. With the time, more motor units must simultaneously recruits for maintaining similar contraction force. By the increase of activation, the intramuscular pressure reduced muscle perfusion and blood flow [1]. Because of the increased muscular oxygen consumption and
\end{abstract}

the reduction of blood flow and perfusion, the muscle oxygenation reduced during isometric contraction (Fig. 1). Forearm muscle oxygenation is observing by using Near infrared spectroscopy (NIRS) instrument (Fig. 2). Our results have shown that forearm oxygenation of experienced alpinists decreased less than in subjects, who did not train regularly their forearms (Fig. 3). The contraction time of alpinists was approximately $30 \%$ longer [2]. Endurance performance of sport climbers can be assessed by using climbing-

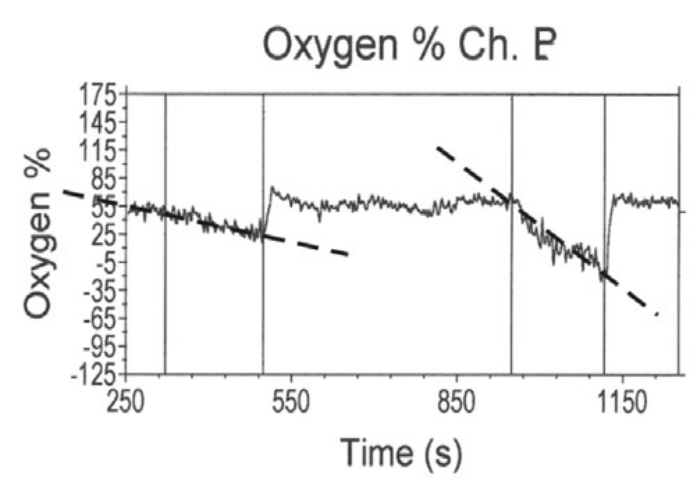

Figure 1. The time course of the relative muscle oxygen saturation $\left(\mathrm{SmO}_{2}\right)$ throughout the isometric contraction. The decrease of $\mathrm{SmO}_{2}$ during contraction and its increase (overshoot) after cessation of contraction determine that phenomenon. 


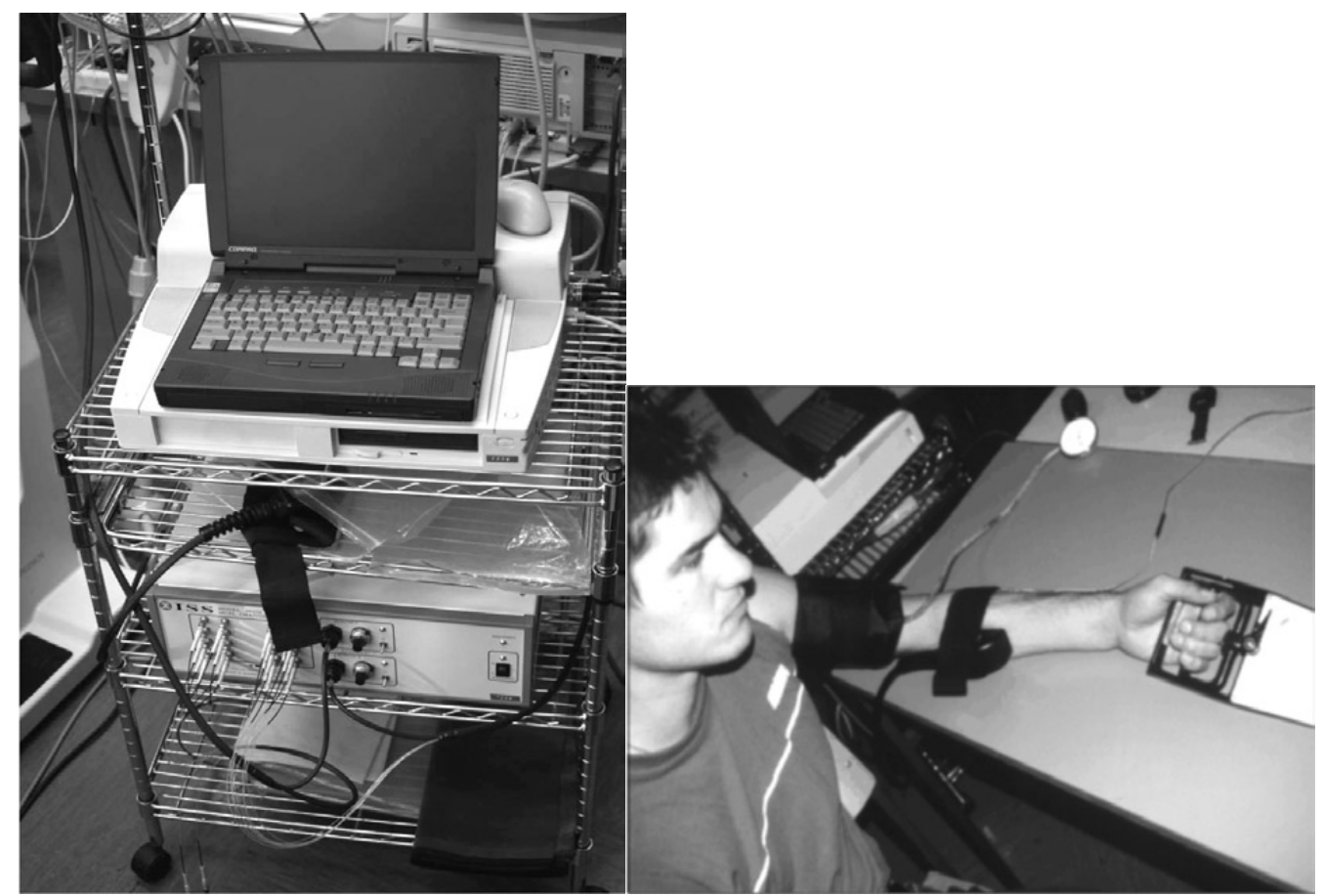

Figure 2. Near infrared spectroscope (NIRS) equipped for measurements of the muscle oxygenation (left) with sensor setting for measurement of forearm oxygenation (right)
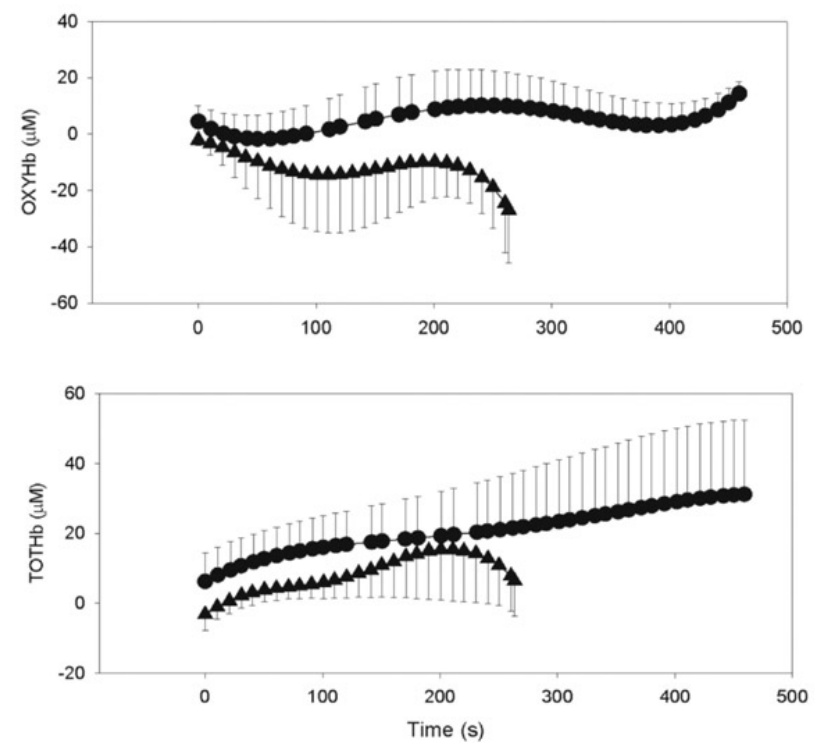

Figure 3. The difference among trained climbers and untrained showed enhanced oxygenation in forearm of trained alpinists

specific test: climbing on climbing wall with changes in elevation (Fig. 4). Local muscular endurance seems to be evaluated in such conditions. The modification of this test is undergoing for the estimating of endurance performance in heavier alpinists.

Endurance performance testing did not show any superiority of high-altitude alpinists' performance in comparison to untrained population [3]. During incremental testing by using treadmill uphill walking with additional $15 \mathrm{~kg}$ backpack [4], we did not find any data which have shown any superiority of climb-

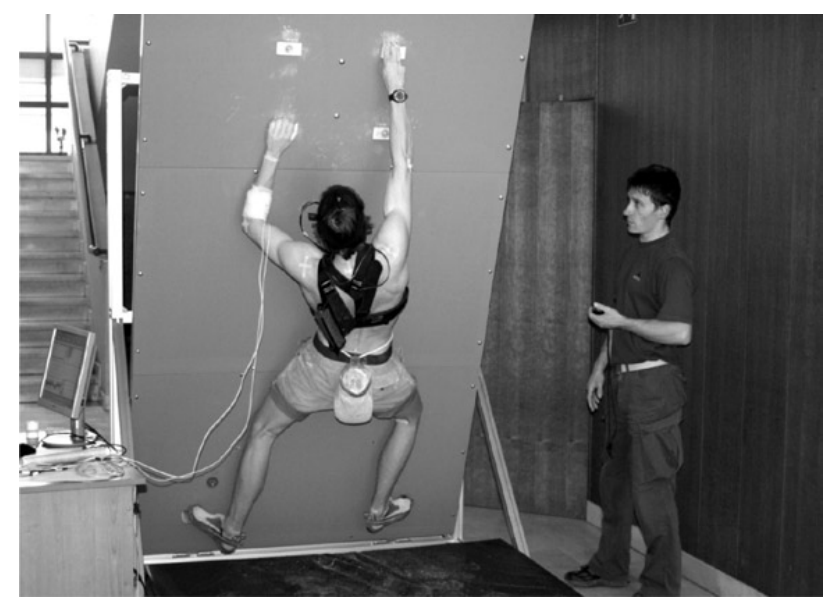

Figure 4. Testing of endurance performance of climbers. The incremental testing protocol on climbing wall is performed.

ers in endurance performance in relation to normal active population values, during testing in normoxic conditions. Aerobic power reached $49 \pm 5 \mathrm{mmol} / \mathrm{l} \cdot \mathrm{min}^{-1}$ and maximal heart rate $183 \pm 8 \mathrm{~min}^{-1}$. High values of maximal oxygen consumption $\left(\dot{\mathrm{VO}}_{2}\right.$ max $)$, which are needed for endurance performance, were not reached also in testing results of climbers and/or high-altitude alpinists. Higher $\dot{\mathrm{V}}_{2}$ max correlated significantly with endurance performance [5] in normoxic conditions and in endurance sports, where the aim of the competition is to finish the event (running, cycling or 
swimming) as soon as possible. Mountain climbing has not such sports characteristics. Climbers never use a significant part of their $\mathrm{V}_{2}$ max during climbing in moderate altitude in spite of wearing the additional weight. High oxygen consumption can reduce arterial oxygen blood saturation during maximal exercise. This happens when enhancement of ventilation cannot deliver of oxygen in a rate to match its uptake by muscles. This is not significant problem during exercise in normoxic conditions, except during certain sports, where exercise hypoxemia occurs during maximal intensities.

\section{Human body response to altitude hypoxia (accli- matization)}

The high-altitude dramatically influences human response during exercise and dramatically reduces its endurance performance. Hypoxia is the main single factor which influenced very complex adaptations called acclimatization. The earliest response of organism on exposure to high-altitude hypoxia results in characteristically increase of ventilation $\left(\mathrm{V}_{\mathrm{E}}\right)[6]$, and heart rate (HR) [5, 7]. Enhanced neural stimulation from baroreceptors and sympatoadrenal activity, which increased $V_{E}$ [6-11] and influences complex changes of gas exchange [12], blood oxygenation $\left(\mathrm{SaO}_{2}\right)$ [6] and acid-base balance [6] through reducing partial pressure of $\mathrm{CO}_{2}\left(\mathrm{PCO}_{2}\right)$ and additional extraction of bicarbonate $\left(\mathrm{HCO}_{3}\right)$ by kidneys [6]. Consequently, different organs, especially exercising muscles and brain changes their oxygenation and circulation $[13,14]$. The phenomenon (acclimatization) occurs in minutes to hours of exposure to altitude hypoxia [6]. Prolonged (days to weeks) living and climbing in altitude influenced further acclimatization by several respiratory, cardiovascular, hematologic, metabolic and structural changes $[6,15-22)$. The most characteristically hematological changes accompanied increase of erythropoietin (EPO), which stimulate the production of erythrocytes [9]. This results in an increase of blood oxygen content $\left(\mathrm{CaO}_{2}\right)$. The most characteristically metabolic change is enhancement of carbohydrates (glucose) as a fuel for energetic mechanisms [23, 24]. Lactate concentration increased during submaximal exercise, but paradoxically decrease after maximal exercise $[25,26]$. Structural changes have been mostly observed by changes in body and muscle mass [20,21, 27] and especially in muscle structure [22]. Classical understanding of phenomenon shows that reduced muscle mass is beneficial for increased oxygen delivery to mitochondria. However, the observation of Hoppeler et al [28] that mitochondria number and mass decreased during hypoxia complicated present understanding of the topics.
Training for improving endurance exercise performance at altitude

Altitude can be divided in two zones: below $3000 \mathrm{~m}$, where hypoxia is no significant influence on low-intense, prolonged exercise such is mountaineering and climbing, and above $3000 \mathrm{~m}$, where hypoxia became a significant factor affected also low intense exercise. In the first zone, classical endurance training increases performance. Our experience have shown [4] that subjects during maximal intense uphill walking from altitude of about 1000 to $2000 \mathrm{~m}$, with additional $15 \mathrm{~kg}$ mass in their backpacks increased climbing velocity $(P<0.05)$, after eight weeks of intense interval training. Running training in experimental group consisted of regular interval training on $300 \mathrm{~m}$ distances and 10 repetitions, with $1 \mathrm{~min}$ resting between runs, 3 times per week in addition to usually performed weekend mountaineering. The control group performed only weekend mountaineering and recreational activities. This improvement was accompanied by increase of $\mathrm{VO}_{2}$ peak (from $49 \pm 6$ to $54 \pm 7 \mathrm{ml} / \mathrm{kg}^{\star} \mathrm{min}^{-1}, P<0.05$ ) reached during treadmill incremental test.

Altitudes below and above $2000 \mathrm{~m}$ are frequently uses for altitude-training [29]. This kind of training is usually used for improving sea-level endurance performance [29]. However, successfulness of such training is very unpredictable.

Up to-date, the preparation for high-altitude climbing did not consist of specific endurance training as method for improving endurance performance at high-altitude. Also, the most successful alpinists as Reinhold Messner have not different from others in their basic endurance preparation and in $\mathrm{Vo}_{2} \max$ [3]. It seems, that high $\mathrm{VO}_{2}$ max values represents a danger for a larger decrease of $\mathrm{SaO}_{2}$ during even low intense exercise at high-altitude. Therefore, the classical endurance training seems to be contraindicative for using it during preparation for high-altitude alpinist expedition. Acclimatization reached during active mountaineering up to the base camp and easy reached surrounding peaks, seems to be a good way in the successful acclimatization and specific endurance training adaptation for high-altitude climbing.

\section{Alpinist performance during hypoxic testing before and after high-altitude alpinist expedition}

Successful acclimatization is the key factor which influences increased endurance performance during high-altitude climbing and testing in hypoxic conditions. Acclimatization usually means a complex response of organism, which enhanced blood oxygen saturation by increasing fast response factors (increasing $\mathrm{V}_{\mathrm{E}}$ and $\mathrm{HR} \ldots$...) during initial minutes to hours of hypoxic exposure [6]. Slower response factors (increases myoglobin, erythrocytes, hemoglobin, 
myoglobin...) react in days to weeks, when organism is exposes to hypoxia [6]. Other factors (decrease of body weight, changed nutrition habits and changed metabolism) may be affected also by exercise in spite of its low absolute intensity. Some of them influences are still unclear (decreased muscle mass, increased or decreased capitalization, increased or decreased mitochondrial density...).

Our experience relates mainly to observation of alpinists during hypoxic testing in deaccliamtization phase [30]. Different characteristics, which are affected by high-altitude acclimatization, training effect and changed nutrition habits, starts to change towards values reached previously, during every-day life, usually at sea-level or moderate altitude. As different factors response to altitude with different dynamics, their

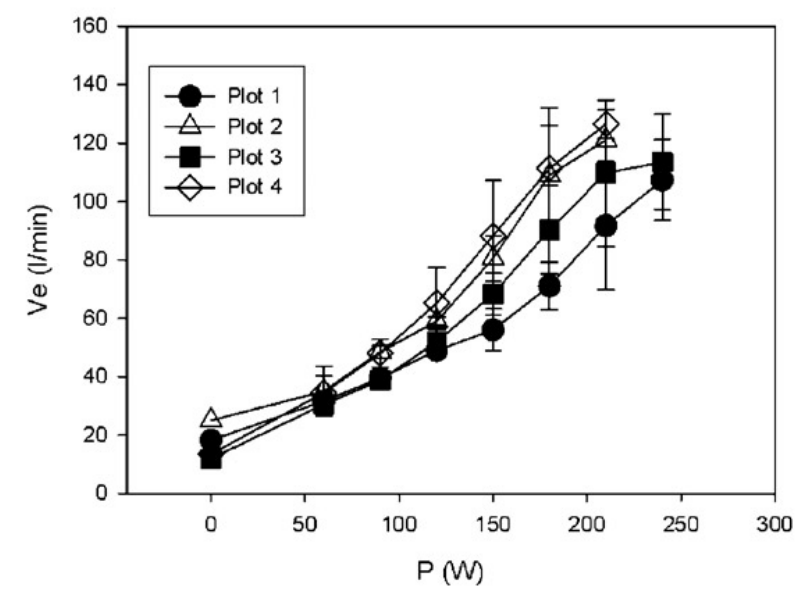

Figure. 5. Ventilation $\left(V_{E}\right)$ observed during incremental testing on cycle ergometer before and after high-altitude expedition in normoxic conditions (filled circles). $V_{E}$ increased above $150 \mathrm{~W}$ after expedition (filled squares). The phenomenon did not occur during testing in hypoxic conditions (open triangles and diamonds). This suggests that the phenomenon was not result of acclimatization.

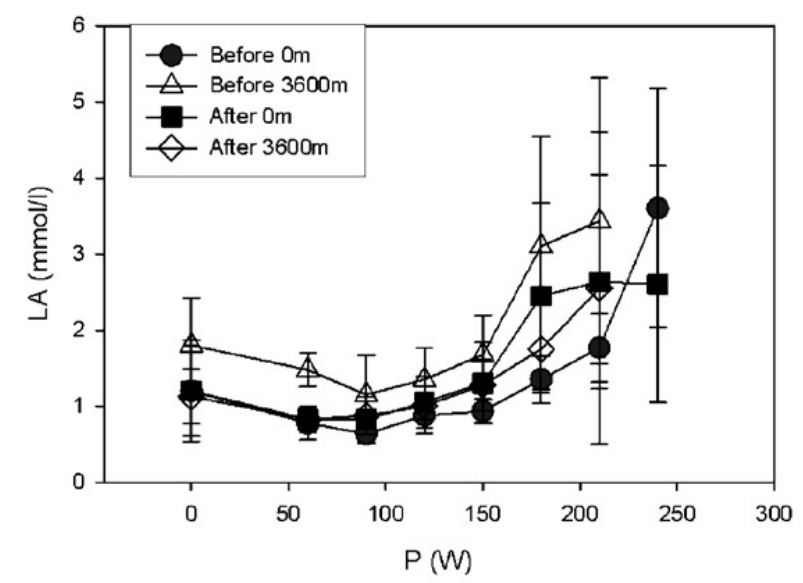

Figure 6. The "lactate curves" obtained during incremental testing on cycle ergometer before high-altitude alpinist expedition during normoxic (filled circles) and after it (filled squares) showed a certain tendency to be increased above $150 \mathrm{~W}$. In contrast, LA after expedition (open diamonds) showed a clear tendency to be reduced, when compared to values before expedition (open triangles). response is also different during deacclimatization. However, this is not a simple mirrored picture [3]. The same characteristics return toward pre-expedition values with different, mostly unknown dynamics then during acclimatization [31]. Several characteristics remained to be different also in a month after returning from high-altitude expedition [30]. Our results show that reduced body weight may persist even a month after returning from high-altitude expedition [30]. This significantly influenced relative power output during testing on cycle-ergometer and may explain even a larger part of increased $\mathrm{V}_{\mathrm{E}}$ during similar absolute submaximal exercise on cycle ergometer (Fig. 5) [30]. In contrary, such explanation seems not be appropriate in explanation of [LA] decrease during submaximal exercise (Fig. 6). The significant part of explanation of this phenomenon seems to be finding in enhanced blood oxygen saturation $\left(\mathrm{SaO}_{2}\right)$, which is still presented an incomplete deacclimatization effect (Fig. 7). This phenomenon is related to increased delivery of oxygen to exercising muscles, enhanced aerobic metabolism and lactate uptake as a fuel [25]. Whether the influence of training and hypoxia during high-altitude expedition affected also brain and muscle oxygenation, has been approved with comparison of muscle and brain oxygenation before and after highaltitude expedition [32]. During $15 \mathrm{~min}$ cycling at 2.4 $\mathrm{W} / \mathrm{kg}$, subjects breathing a hypoxic gas mixture $\left(\mathrm{FiO}_{2}\right.$ $=0.15$ ) for a 5 min interval (Fig. 8). The results showed a reduction in oxygen saturation in both organs. Brain oxygenation was not affected by high-altitude expedition, but muscle oxygenation showed a clear tendency for increasing, which resulted in significantly higher oxygen saturation $\left(\mathrm{SmO}_{2}\right)$ after the cessation from hypoxic mixture and start breathing air again (Fig. 9).

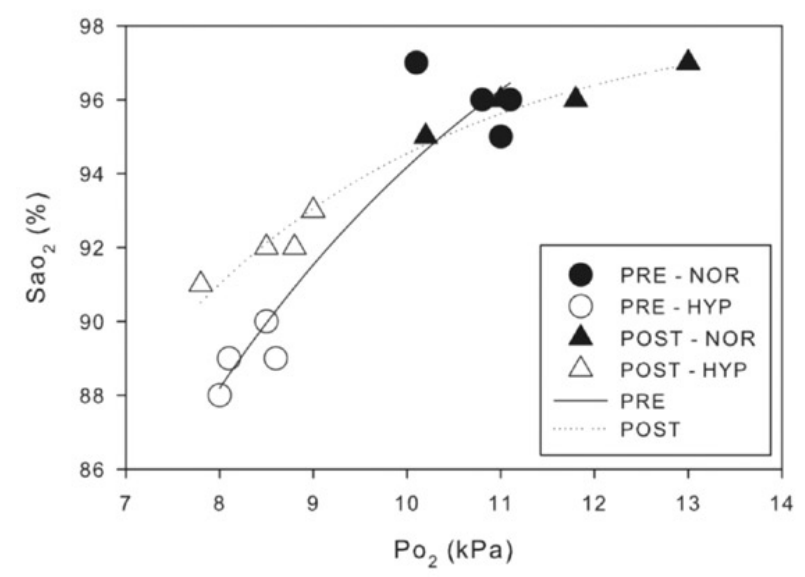

Figure 7. Arterial oxygen saturation $\left(\mathrm{SaO}_{2}\right)$ increased during similar oxygen partial pressure $\left(\mathrm{PO}_{2}\right)$ during exercise in acute hypoxic conditions. This showed an acclimatization effect occurred during high-altitude expedition, which still persisted a month of deacclimatization. 

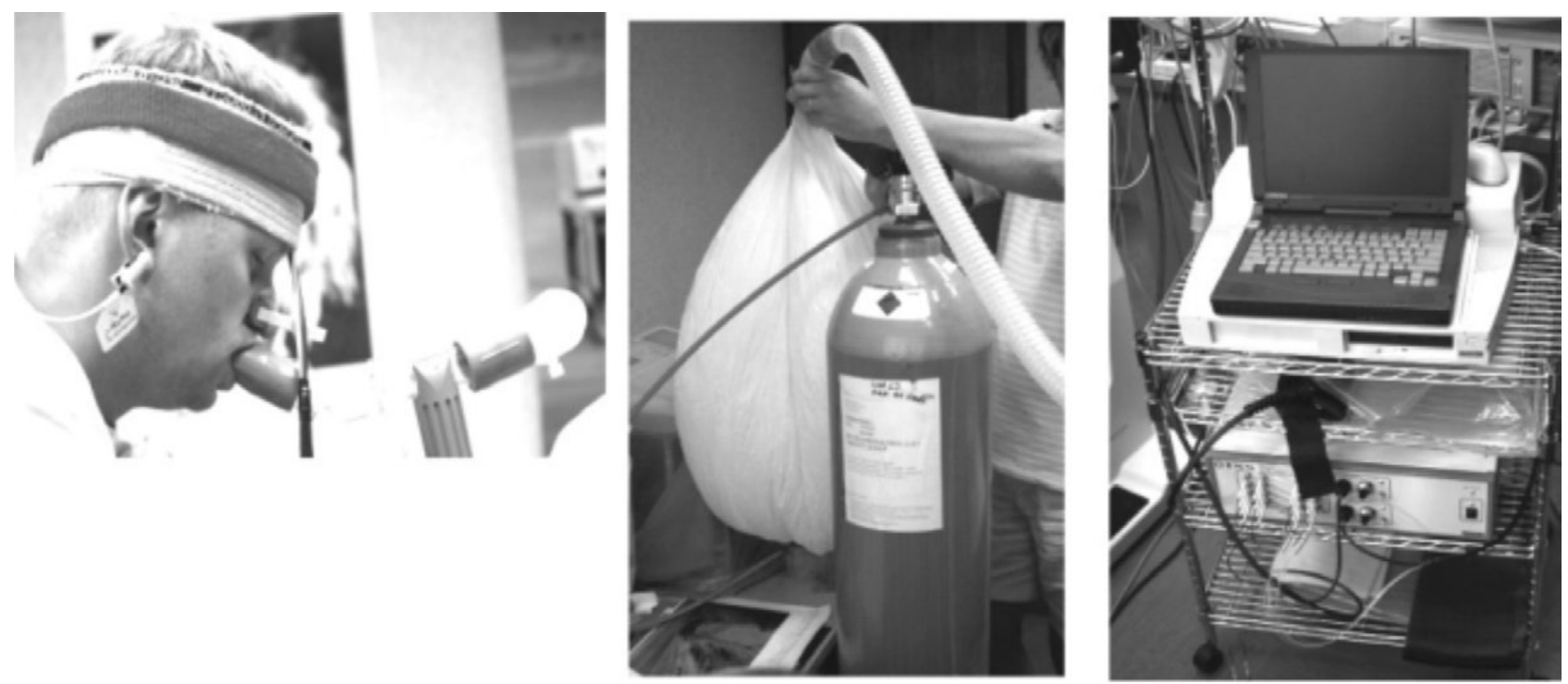

Figure. 8. Breathing hypoxic gas mixture makes possible to ascertain acute changes of arterial blood oxygen saturation by using pulse oxymetry (left) and brain oxygenation by using NIRS instrument and brain sensor (left), caused by breathing hypoxic gas mixture (middle)
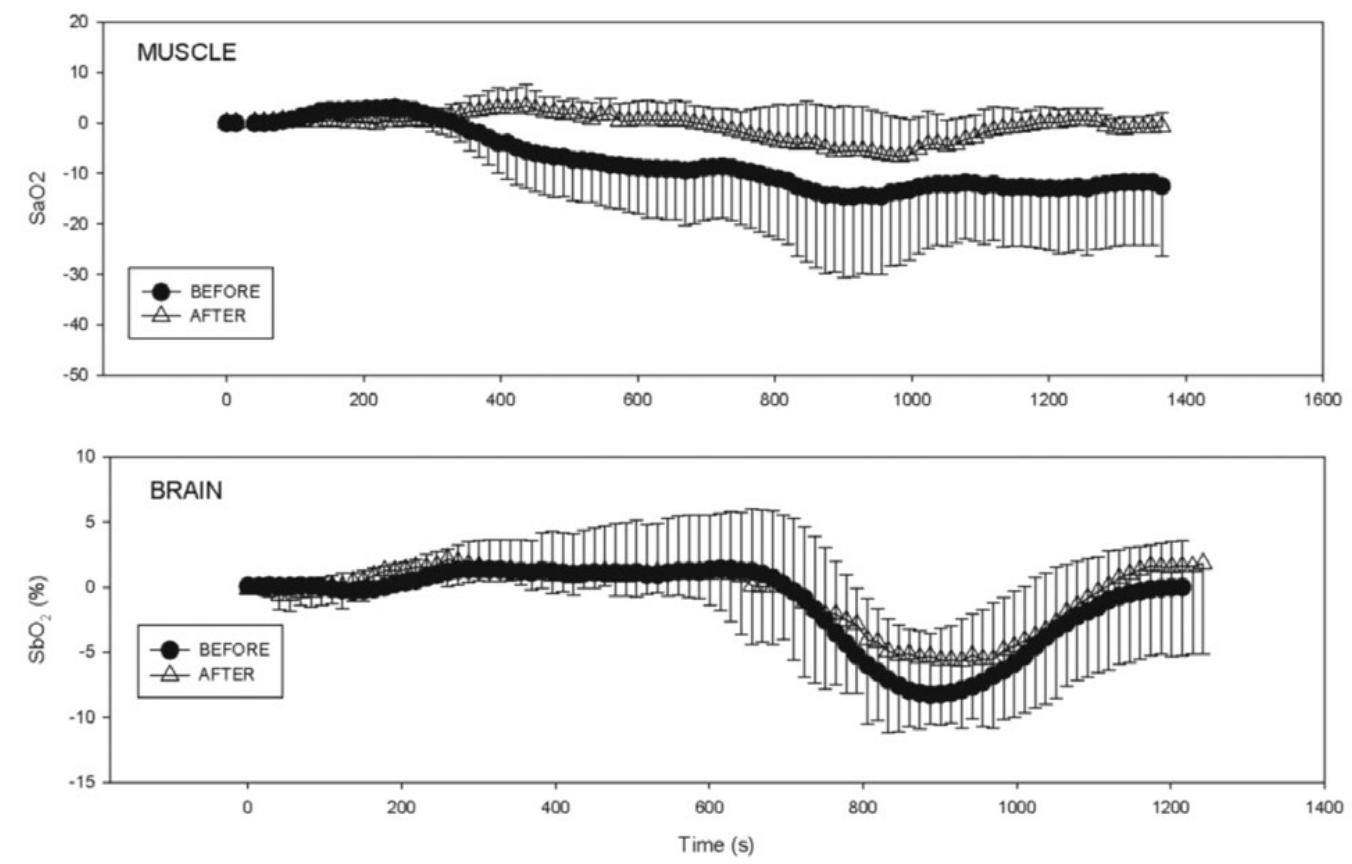

Figure. 9. Muscle and brain relative oxygenation during cycling on ergometer. Exercise started with a 5 min exercise and breathing normoxic air, followed by a three minutes of breathing hypoxic gas mixture $\left(\mathrm{FiO}_{2}=0.15\right)$ and next 5 min of normoxic air. The differences before (filled circles) and after (open triangles) high-altitude expedition occur in muscle oxygenation, but not in the brain.

\section{Conclussion}

Testing of alpinists before and after their high-altitude expeditions brings some novel information in observation of human body adaptations to high-altitude: a possibility for observations of deacclimatization phenomenon. Observing subjects during exercise in normoxic conditions makes possible to follow up adaptations to exercise performed during high-altitude expedition. Such adaptations are result of several weeks of performing concentric muscle contractions, several hours per day and adaptations on mostly eccentric muscular contractions during returning from high-altitude mountain. In a certain part, muscles were affected also by acclimatization (enhanced myoglobin). Observing subjects during exercise in hypoxic conditions makes possible observation of acclimatization and training effect simultaneously, without possibility for separating information. Therefore, with combination of both, a certain new possibility is open, especially when measurements are repeated during deacclimatization. Time course of deacclimatization is very important in military and rescue operations when activities in altitude are often combined with activities at lower altitudes (modern helicopter transportations). 
In this case the reacclimatization seems to be a new important phenomenon for observing.

\section{References}

1. Sjogaard G, Savard G, Carsten J. Muscle blood flow during isometric activity and its relation to muscle fatigue. Eur J Appl Physiol 1988; 57: 327-35.

2. Ušaj A. Differences in the oxygenation of the forearm muscle during isometric contractions in trained and untrained muscles. Cell Mol Biol Lett 2002; 7(2): 375-7.

3. Howald $\mathrm{H}$, Hoppeler H. Performing at extreme altitude: muscle cellular and subcellular adaptations. Eur J Appl Physiol 2003; 90: 360-4.

4. Cukjati I, Ušaj A. High altitude influence on human performance: science and praxis IV. Book of abstracts. Ljubljana: University of Ljubljana, 2009: 22.

5. Astrand P O, Rodahl K, Rahl HA, Strom SB. Textbook of work physiology. Champaign, IL: Human Kinetics, 2003: 441-5.

6. Smith CA, Dempsey JA, Hornbein TF. Control of breathing at high altitude. In: High Altitude - An Exploration of Human Adaptation. Hornbein TH, Schoene RB., ed. New York: Marcel Dekkerr Inc, 2001: 139-50.

7. Hainsworth R, Drinkhill MJ, Rivera Chira. The autonomic nervous system at high altitude. Clin Autonom Res 2007; 17: 13-9.

8. Lahiri S, Cherniak NS. Cellular and molecular mechanisms of $\mathrm{O}_{2}$ sensing with special reference to the carotid body. In: Hornbein TH and Schoene RB., ed. High Altitude - An Exploration of Human Adaptation. New York: Marcel Dekkerr Inc, 2001: 101-30.

9. Dempsey JA, Forster HV. Mediation of ventilatory adaptations. Physiol Rev 1982; 62(1): 262-46.

10. Hornbein T H, Schoen R B. High Altitude - An Exploration of Human Adaptation. In: Hornbein TH and Schoene RB., ed. High Altitude - An Exploration of Human Adaptation. New York: Marcel Dekkerr Inc, 2001.

11. Katayama K, Yasotake S, Mororome Y, et al. Ventilatory chemosensitive adaptation to intermittent hypoxic exposure with endurance training and detraining. J Appl Physiol 1999; 86(6): 1805-11.

12. Wagner P. Gas exchange. In: Hornbein TH and Schoene RB., ed. High Altitude - An Exploration of Human Adaptation. New York: Marcel Dekkerr Inc, 2001: 199-234.

13. Paulin MJ, Robbins PA. Influence of cerebral blood flow on the ventilatory response to hypoxia in humans. Exp Physiol 1998; 83: 95-106.

14. Severinghaus JW. Cerebral circulation at high altitude. In: Hornbein TH and Schoene RB., ed. High Altitude - An Exploration of Human Adaptation. New York: Marcel Dekkerr Inc, 2001: 343-75.

15. Murray, J.F. The normal lung. Philadelphia: W. B. Saunders Company,1986.

16. Vogel JA, Harris CW. Cardiopulmonary response of resting man during early exposure to high altitude. J Appl Physiol 1967; 22(6): 1124-8.

17. Roach RC. Cardiovascular regulation during hypoxia. In: Saltin B, Boushel R, Secher N, Mitchell J., ed. Exercise and circulation in health and disease. Human Kinetics, 2000

18. Terrados N, Jannsen E, Sylven C, Kaijser L. Is hypoxia a stimulus in synthesis of oxidative enzymes and myoglobin? J Appl Physiol 1990; 68(6): 2369-72.
19. Groover RF, Bartsch P. Blood. In: Hornbein TH and Schoene RB., ed. High Altitude - An Exploration of Human Adaptation. New York: Marcel Dekkerr Inc, 2001: 493-523.

20. Bales B, Hackney AC, Coyne JT, et al. Mountaineering sojourn: effects on body composition of prolonged exposure to high altitude in a cold environment. J Wild Med 1993; 4: 32-9.

21. Boyer SJ, Blume FD. Weight loss and changes in body composition at high altitude. J Appl Physiol 1984; 57(5): 1580-5.

22. Green H J, Sutton J R. The effects of altitude on skeletal muscle. In: Hornbein TH and Schoene RB., ed. High Altitude - An Exploration of Human Adaptation. New York: Marcel Dekkerr Inc, 2001: 443-92.

23. Brooks GA, Butterfield GE, Wolfe RR, et al. Increased dependence on blood glucose after acclimatization to $4300 \mathrm{~m} . J$ Appl Physiol 1991; 70(2): 919-27.

24. Broun B. Effects of high altitude on substrate use and metabolic economy: cause and effect? Med Sci Sports Exerc 2008; 40(8): 1495-500.

25. Brooks GA, Fahey TD, White TP. Exercise physiology. Human bioenergetics and its adaptations. Mountain View: Mayfield Publishing Company, 1996.

26. Grassi B, Marzorati M, Kayser B, et al. Peak blood lactate and blood lactate vs. workload during acclimatization to $5050 \mathrm{~m}$ and in deacclimatization. J Appl Physiol 1996; 80(2): 685-92.

27. Schols AMW, Westerterp KR. Hypoxia, nitrogen balance and body weight. Eur J Appl Physiol 2002;20: 252-3.

28. Hoppeler H, Vogt M, Weibel ER, Fluck M. Response of skeletal muscle mitochondria to hypoxia. Exp Physiol 2003; 88(1): 109-19.

29. Willber RL. Altitude training and athletic performance. Champaigne IL: Human Kinetics, 2004.

30. Usaj A, Burnik S. Blood oxygen saturation and heart rate during exercise in normoxia and normobaric hypoxia a month after a high-altitude alpinist expedition. Kinesiology 2009 (in press).

31. Beidleman B, Muzo SR, Pack PB, et al. Extreme responses after altitude acclimatization are retained during reintroduction to altitude. Med Sci Sports Exerc 1997; 19(11): 1588-95.

32. Usaj A. The influence of acute hypoxia on arterial, muscle and brain oxygenation before and after high-altitude alpinist expedition. Mountain, Sport and Health, Book of abstracts, Rovereto, 2009: 55.

Received: December 04, 2009

Accepted: March 25, 2010

Published: March 31, 2010

Address for correspondence:

Anton Ušaj

Laboratory of Biodynamics,

Faculty of Sport,

Gortanova 22

1000 Ljubljana

SLOVENIA

e-mail: anton.usaj@siol.net

\begin{tabular}{llll}
\hline Authors' contribution & B - Data Collection & D - Data Interpretation & F - Literature Search \\
A - Study Design & C - Statistical Analysis & E - Manuscript Preparation & G - Funds Collection
\end{tabular}

